\title{
Compartment fire temperature - a new simple calculation method
}

\author{
ULF WICKSTRÖM ${ }^{a, b}$ and ALEXANDRA BYSTRÖM ${ }^{a}$ \\ ${ }^{a}$ Division of Structural and Construction Engineering / Department of Civil, Environmental and \\ Natural resources engineering \\ Luleå University of Technology, Sweden \\ ${ }^{\mathrm{b}}$ Fire Technology, SP, Sweden
}

\begin{abstract}
In this paper a new simple calculation method for compartment temperatures is derived. The method is applicable to post-flashover ventilation controlled fires. A parameter termed the ultimate compartment fire temperature is defined as the temperature obtained when thermal equilibrium is reached and thick compartment boundaries cannot absorb any more heat from the fire gases. This temperature depends only on the product of the heat of combustion and the combustion efficiency over the specific heat capacity of air. It is, however, independent of the air mass flow rate, and of the fire compartment geometry and the thermal properties of the compartment boundary materials. These parameters on the other hand govern the rate at which the fire temperature is increasing towards the ultimate temperature.

It is shown how the fire temperature development as a function of time in some idealized cases may be calculated by a simple analytical closed form formula.

The fire temperature developments of two types of compartment boundaries are presented, semi-infinitely thick and thin structures. It is also shown that for the semi-infinite case, the solution resembles the standard ISO 834/EN 1363-1 curve and the parametric fire curves according to Eurocode 1, EN 1991-1-2.
\end{abstract}

KEYWORDS: one-zone fire model, compartment fire temperature, analytical solution.

\section{NOMENCLATURE}

$\begin{array}{llll}A_{o} & \begin{array}{l}\text { area of openings }\left(\mathrm{m}^{2}\right) \\ \text { total surrounding area of enclosure }\end{array} & T & \text { temperature }\left({ }^{\circ} \mathrm{C}\right) \\ A_{t o t} & \left(\mathrm{~m}^{2}\right) & T_{g} & \text { gas temperature }\left({ }^{\circ} \mathrm{C}\right) \\ c & \text { specific heat capacity }(\mathrm{J} /(\mathrm{kg} \mathrm{K})) & T_{f} & \text { fire temperature }\left({ }^{\circ} \mathrm{C}\right) \\ & \begin{array}{l}\text { specific heat at constant pressure } \\ (\mathrm{J} /(\mathrm{kg} \mathrm{K}))\end{array} & T_{i} & \text { initial temperature }\left({ }^{\circ} \mathrm{C}\right) \\ c_{p} & T_{\infty} & \text { ambient temperature }\left({ }^{\circ} \mathrm{C}\right) \\ H_{o} & \text { height of the openings }\left(\mathrm{m}^{2}\right) & t & \text { time }(\mathrm{s}) \\ h & \text { heat transfer coefficient }\left(\mathrm{W} / \mathrm{m}^{2} \mathrm{~K}\right) & \text { Greek } & \\ k & \text { thermal conductivity }(\mathrm{W} /(\mathrm{m} \mathrm{K})) & \alpha_{1} & \text { flow constant } \\ \dot{m}_{a} & \text { Mass flow rate of gases }\left(\mathrm{kg} / \mathrm{m}^{2}\right) & & \text { constant describing the combustion } \\ & & & \text { energy developed per unit mass of } \\ \dot{m}_{l} & \text { Mass flow rate in compartment }\left(\mathrm{kg} / \mathrm{m}^{2}\right) & \alpha & \text { air } \\ \dot{m}_{o} & \text { Mass flow rate out }\left(\mathrm{kg} / \mathrm{m}^{2}\right) & \chi & \text { combustion efficiency }(-) \\ O & \text { opening factor } & \varepsilon & \text { emissivity }(-) \\ R & \text { thermal resistance }\left(\left(\mathrm{m}^{2} \mathrm{~K}\right) / \mathrm{W}\right) & \theta & \text { temperature increase }(\mathrm{K}) \\ R_{f} & \text { fire heat transfer resistance }\left(\left(\mathrm{m}^{2} \mathrm{~K}\right) / \mathrm{W}\right) & \rho & \text { density }\left(\mathrm{kg} / \mathrm{m}^{3}\right) \\ R_{h, i} & \text { heat transfer thermal resistance at the } & & \text { Stefan-Boltzmann constant }\left(\mathrm{W} /\left(\mathrm{m}^{2}\right.\right. \\ \dot{q}_{w}^{\prime \prime} & \text { fire exposed surface }\left(\left(\mathrm{m}^{2} \mathrm{~K}\right) / \mathrm{W}\right) & \sigma & \left.\left.\mathrm{K}^{4}\right)\right) \\ \dot{q}_{c} & \text { the heat transfer at surface }\left(\mathrm{W} / \mathrm{m}^{2}\right) & \tau & \text { time constant }(\mathrm{sec}) \\ \dot{q}_{l} & \text { heat release rate by combustion }(\mathrm{W}) & \text { Subscripts }\end{array}$


$\dot{q}_{r}$ heat radiation out through the openings

(W)

$\dot{q}_{w}$

losses to the surrounding structure (W) $s$

ult fire exposed surface

ultimate

\section{INTRODUCTION}

Fire engineering design of structures and structural elements are in most cases made with a procedure including a classification system and associated standard tests like ISO 834, EN 1363-1 or ASTM E-119 with defined time-temperature fire exposures. In these tests fully developed enclosure fires are simulated in fire resistance furnaces with a prescribed duration. Other design fires are obtained by making a heat and mass balance analysis of fully developed compartment fires. A number of significant simplifications and assumptions are then done to limit the number of input parameters and facilitate the calculations. Thus

1. The fire compartment is ventilated by natural convection at a constant rate independent of temperature.

2. The combustion rate is ventilation controlled, i.e. proportional to the ventilation rate.

3. The gas temperature is uniform in the fire compartment.

4. The energy of the fuel is released entirely inside the compartment.

5. The surface temperature of the enclosure structure is assumed equal to the gas temperature.

6. The fire duration is proportional to the amount of energy in the combustibles in the compartment, i.e. the fuel load.

The main purpose of this paper is not to suggest another set of design curves but rather to show and demonstrate how a well-defined analysis of the energy and mass balances of a fire compartment can lead in the end to relatively simple mathematical solutions which includes the key physical and chemical input parameters. In addition it is shown how the model relates to current standard time-temperature curves.

\section{GENERAL THEORY OF ONE-ZONE MODELS}

The theory and assumptions outlined below follows broadly the work of Magnusson and Thelandersson [1] who developed a numerical compartment fire model already in the early 1970's. They then calculated fire temperature-time curves for compartments and compared with numerous experimental data. Their model and curves was then modified and reformulated according to later work by Wickström [2]. This work is the basis for the design fires referred to in Eurocode 1, EN 1991-1-2, Appendix A as 'parametric temperaturetime curves' [3]. The fundamentals of the theory are presented below. For details on the so called parametric fires the reader is referred to the EN standard. The here suggested values of model parameters are mainly taken from the original works of Magnusson and Thelandersson [1] or when possible from general adequate text-books.

The heat balance of a fully developed fire as shown in Fig. 1 may be written as:

$\dot{q}_{c}=\dot{q}_{l}+\dot{q}_{w}+\dot{q}_{r}$

where $\dot{q}_{c}$ is the heat release rate by combustion, $\dot{q}_{l}$ the heat loss rate by the flow of hot gases out of the compartment openings, $\dot{q}_{w}$ the losses to the surrounding structure and $\dot{q}_{r}$ the heat radiation out through the openings. Other components of the heat balance equation are in general insignificant and not included in a simple analysis as this.

Air and combustion products flow in and out of the compartment driven by buoyancy, i.e. the pressure difference developed between the inside and outside of the compartment due to temperature difference as indicated in Fig. 1. The mass flow rates in $\dot{m}_{l}$ and out $\dot{m}_{o}$ must be equal (the mass of the gases generated by the fuel is neglected) and is designated hereafter $m_{a}$. The mass flow rates through vents are computed by applying the Bernoulli's principle. Calculation methods for vertical openings can be found in the literature [4]. For vertical openings the flow rate can be derived as approximately proportional to the opening area times the square root of its height:

$$
\dot{m}_{a}=\alpha_{1} A_{o} \sqrt{H_{o}}
$$


where the proportionality constant $\alpha_{1}$ is a flow constant, $A_{o}$ and $H_{o}$ are the area and height of the openings of the compartment. The value of $\alpha_{1}$ at high uniform gas temperature can be found to be approximately 0.5 [4]. The dependence of $\alpha_{1}$ on the fire temperature level is assumed small over a wide range and is therefore neglected here as in most analyses of this kind. (For details on e.g. multiple openings and horizontal openings, see e.g. EN 1991-1-2 Appendix A)

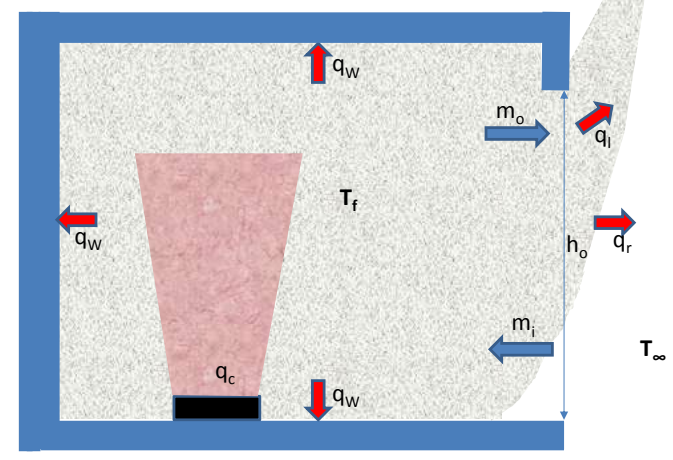

Fig. 1. One-zone model of a fully developed compartment fire with a uniform temperature $T_{f}$.

As the fire is ventilation controlled the combustion rate $\dot{q}_{c}$ inside the compartment is proportional to the air flow into the compartment, i.e.:

$$
\dot{q}_{c}=\chi \alpha_{2} \dot{m}_{a}=\chi \alpha_{2} \alpha_{1} A_{o} \sqrt{H_{o}}
$$

where $\chi$ is the combustion efficiency and $\alpha_{2}$ is a constant describing the combustion energy developed per unit mass of air. The latter varies very little for various fuels/materials [5]. This fact is also accounted for when measuring heat release rates by the so called oxygen depletion technique as in e.g. a cone calorimeter test according to ISO 5660. According to Tewarson [6], the combustion efficiency values are in the range of $3 \%$ to $30 \%$ for hard combustible materials and up to $93 \%$ for some liquid fuels. By narrowing the range of the efficiency, combustion can be assumed in the range $40 \%-70 \%$ [7]. To fit the existing parametric fire curve, the combustion efficiency for that model has been chosen about 0.5 .

The convection loss term is proportional to the mass flow times the fire temperature increase, i.e:

$\dot{q}_{l}=c_{p} \dot{m}_{a}\left(T_{f}-T_{i}\right)=c_{p} \alpha_{1} A_{o} \sqrt{H_{o}} \theta_{f}$

where $c_{p}$ is the specific heat capacity of the combustion gases (usually assumed equal to that of air), $T_{f}$ and $T_{i}$ are the fire and the initial (and ambient) temperatures, respectively. $\theta_{f}$ is the fire temperature increase, i.e:

$\theta_{f}=T_{f}-T_{i}$

The wall loss term $\dot{q}_{w}$ is proportional to the total surrounding area of the enclosure $A_{t o t}$ :

$\dot{q}_{w}=A_{t o t} \dot{q}_{w}^{\prime \prime}$ 
where $\dot{q}_{w}^{\prime \prime}$ is the heat flux rate to the enclosure surfaces. This term constitutes the inertia of the system. It is significant in the beginning of a fire and then it decreases when the temperature of the surrounding structure increases along with the fire temperature.

The heat radiation out through the openings may be calculated as:

$$
\dot{q}_{r}=A_{o} \sigma\left(T_{f}^{4}-T_{\infty}^{4}\right)
$$

\section{DESCRIPTION OF THE NEW ONE-ZONE MODEL}

The model is based on the theory described above. By inserting Eq. 3, Eq. 4, Eq. 6 and Eq. 7 into Eq. 1, and after rearranging the heat balance equation of a fire compartment may be written as:

$\dot{q}_{w}^{\prime \prime}=c_{p} \alpha_{1} O\left(\frac{\chi \alpha_{2}}{c_{p}}-\theta_{f}\right)+\frac{A_{o}}{A_{t o t}} \sigma\left(T_{\infty}^{4}-T_{f}^{4}\right)$

where $O$ is named the opening factor defined as:

$O=\frac{A_{o} \sqrt{H_{o}}}{A_{t o t}}$

When the losses to the compartment boundaries $\dot{q}_{w}$ and the radiation losses $\dot{q}_{r}$ are negligible what is named the ultimate compartment fire temperature $\theta_{u l t}$ is obtained. It can be derived from Eq. 8 as:

$$
\theta_{u l t}=\frac{\chi \alpha_{2}}{c_{p}}
$$

In general the compartment fire temperature reaches its maximum when $\dot{q}_{w}$ is at its minimum value. This happens when the surrounding structures after some time have been fully heated and stationary thermal conditions can be assumed. Note that if the losses through the surrounding structure and the radiation out the window can be neglected, then the fire temperature depends only on the ratio between $\left(\chi \alpha_{2}\right)$ and $c_{p}$, i.e. ratio between the effective heat of combustion per unit weight of air and the specific heat of the fire gases. Thus the ultimate fire temperature becomes independent of the opening factor and the thermal properties of the surrounding structure.

The flow constant $\alpha_{1}$ may be derived for flow in and out through a vertical square opening due to the pressure differences between the inside and outside of the fire compartment due to the temperature differences [4], see Fig. 1. The combustion yield constant $\alpha_{2}$ is obtained from the knowledge that most organic materials yield about $13.1 * 10^{6} \mathrm{Ws} / \mathrm{kg}$ oxygen under ideal combustion conditions [5]. The yield constant $\alpha_{2}$ is calculated assuming an oxygen content of $23 \%$ in ambient air. When the combustion efficiency constant $\chi$ is assumed to be in the order of $50 \%$, to the calculated temperatures fit with the Eurocode parametric fire curves. The specific heat capacity of air at constant pressure $c_{p}$ is here taken from tabulated values at a temperature level of $800^{\circ} \mathrm{C}$, i.e. $c_{p}=1.15^{*} 10^{3} \mathrm{Ws} /(\mathrm{kg} \mathrm{K})$ [8].

The values of all the three constants introduced above vary only slightly with temperature (the value av $c_{p}$ varies from $1.00^{*} 10^{3}$ at $20^{\circ} \mathrm{C}$ to $1.68 * 10^{3}$ at $2500{ }^{\circ} \mathrm{C}$ [8]) and are therefore here assumed to remain unaffected with changing temperatures. Commonly assumed values are summarized in Table 2.

\section{Analogious model}

Eq. 8 is analogous to the heat transfer equation by convection between a gas and a solid surface. Under certain conditions as demonstrated below the fire temperature can then be obtained by analytical methods as shown below. Under other conditions numerical methods are needed. Then the parameter group $c_{p} \alpha_{1} O$, is analogous to a heat transfer coefficient. For clarity it is convenient to work with thermal resistances and 
analogies with electrical resistances. Thus an artificial thermal resistance here named the fire heat transfer resistance is introduced:

$$
R_{f}=\frac{1}{c_{p} \alpha_{1} O}
$$

The thermal conditions may be seen as an analogous electrical model as shown in Figure 2. $R_{h, i}$ in the figure denotes the heat transfer thermal resistance at the fire exposed surface. Then the heat transfer at the surface becomes:

$\dot{q}_{w}^{\prime \prime}=h_{i}\left(\theta_{f}-\theta_{s}\right)$

where

$h_{i}=\frac{1}{R_{h, i}}$

Now Eq. 8 may combined with Eq. 11, Eq. 12 and Eq. 13 to yield:

$\dot{q}_{w}^{\prime \prime}=\frac{1}{R_{f}+R_{h, i}}\left(\theta_{u l t}-\theta_{s}\right)+\frac{A_{o}}{A_{t o t}} \frac{1}{\left(1+\frac{R_{h, i}}{R_{f}}\right)} \sigma\left(T_{\infty}^{4}-T_{f}^{4}\right)$

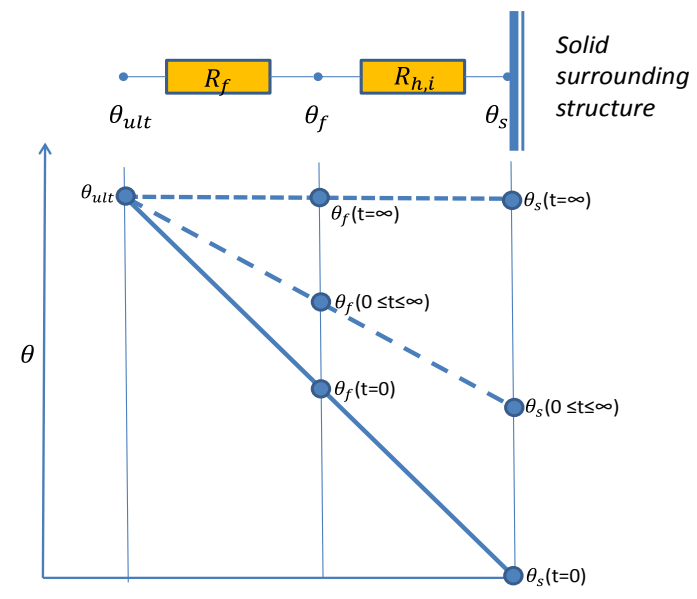

Fig. 2. Electrical analogy of fire model of thick structure assumed to be infinitely thick, and an indication of the temperature initially $(t=0)$, after some time $(0 \leq t \leq \infty)$ and after a very long time $(t=\infty)$.

This relation can be interpreted as a boundary condition for the surrounding structure where the parameters can be identified as given in Table 1 and 2 . In Figure 2 it is indicated that the fire temperature can be calculated by rule of proportion as:

$\theta_{f}=\frac{\theta_{s} R_{f}+\theta_{u l t} R_{h, i}}{R_{f}+R_{h, i}}=\frac{\theta_{s} h_{i}+\theta_{u l t} h_{f}}{h_{f}+h_{i}}$

One observation is that this theory yields an instant fire temperature increase $\theta_{f}^{0}$ : 
Table 1. Analogue parameters

\begin{tabular}{|c|c|c|}
\hline Parameter & Analogue parameter & Analogue notation \\
\hline$\frac{1}{R_{f}+R_{h, i}}=\frac{1}{\frac{1}{c_{p} \alpha_{1} O}+\frac{1}{h_{i}}}$ & $\begin{array}{c}\text { Convection heat transfer } \\
\text { coefficient }\end{array}$ & $h_{c o n}$ \\
\hline$\theta_{u l t}+T_{i}=\frac{\alpha_{2}}{c_{p}}+T_{i}$ & Ultimate fire temperature increase & $T_{g}$ \\
\hline$\frac{A_{o}}{A_{t o t}}\left(1+\frac{R_{h . i}}{R_{f}}\right)$ & Emissivity & $\varepsilon$ \\
\hline$T_{\infty}$ & Ambient radiation temperature & $T_{\infty}$ \\
\hline
\end{tabular}

Table 2. Assumed values of parameters in the simple one-zone fire

\begin{tabular}{|l|c|c|c|}
\hline \multicolumn{1}{|c|}{ Name } & Notation & Value & SI-units \\
\hline Flow constant & $\alpha_{1}$ & 0.5 & $\left.\mathrm{~kg} /(\mathrm{s} \mathrm{m})^{1 / 2}\right)$ \\
\hline Combustion yield & $\alpha_{2}$ & $3.013^{*} 10^{6}$ & $\mathrm{Ws} / \mathrm{kg}$ \\
\hline Specific heat capacity of air & $c_{p}$ & 1150 & $\mathrm{Ws} /(\mathrm{kg} \mathrm{K})$ \\
\hline Ultimate fire temperature increase (Eq. 10) & $\theta_{u l t}=\chi \alpha_{2} / c_{p}$ & $1325(\chi=0.505)$ & $\mathrm{K}$ \\
\hline Analogue heat transfer coefficient & $\frac{1}{1}$ & -1 & $\mathrm{~W} /\left(\mathrm{m}^{2} \mathrm{~K}\right)$ \\
& $\frac{1}{c_{p} \alpha_{1} O}+\frac{1}{h_{i}}$ & & \\
\hline Analogue heat transfer coefficient given, $R_{h, i}=0$ & $h_{f}=c_{p} \alpha_{1} O$ & $575^{*} \mathrm{O}$ & $\mathrm{W} /\left(\mathrm{m}^{2} \mathrm{~K}\right.$ \\
\hline Analogue heat transfer resistance given, $R_{h, i}=0$ & $R_{f}=1 / c_{p} \alpha_{1} O$ & $0.00174 / \mathrm{O}$ & $\left(\mathrm{m}^{2} \mathrm{~K}\right) / \mathrm{W}$ \\
\hline
\end{tabular}

$\theta_{f}^{0}=\frac{R_{h, i}}{R_{f}+R_{h, i}} \theta_{u l t}=\frac{h_{f}}{h_{f}+h_{i}} \theta_{u l t}$

This is of course only physically correct if the initial combustion developing process (i.e. the ignition and growth stages) is ignored. However, as soon as the combustion and the flow are established and flashover has occurred and stabilized the approximate predictions given by the above theory are expected to apply. The analogue parameters are summarized in Table 1 and typical parameter values in Table 2.

\section{EXAMPLES OF USING OF THE NEW CALCULATION METHODS}

Below two idealized cases of compartment boundaries will be presented, one assuming compartment boundaries being semi-infinitely thick, and one assuming compartment boundaries being thin where the heat capacity is concentrated in a core, so called lumped heat capacity. Analytical solution of the fire temperature can then be derived if constant properties including heat transfer coefficients are assumed.

\section{Semi-infinitely thick compartment boundaries}

For typical fire durations, the compartment boundaries may be considered thermally thick and heat transferred to the surfaces and stored in the surrounding structures. The heat flux to the compartment boundaries can be written as: 
$\dot{q}_{w}^{\prime \prime}=-k\left(\frac{d T}{d x}\right)_{x=0}$

Now the approximation is made that the temperatures of the surrounding surfaces are assumed equal to the fire temperature, i.e. the heat transfer resistance between the fire gases and the surface of solid compartment boundary is neglected $\left(R_{h, i}=0\right.$ and $\left.\theta_{f}=\theta_{s}\right)$. In addition the radiation loss term out the openings is neglected. Then Eq. 14 becomes:

$\dot{q}_{w}^{\prime \prime}=\frac{1}{R_{f}}\left(\theta_{u l t}-\theta_{s}\right)$

A diagram of the corresponding electrical analogy is shown in Figure 3.

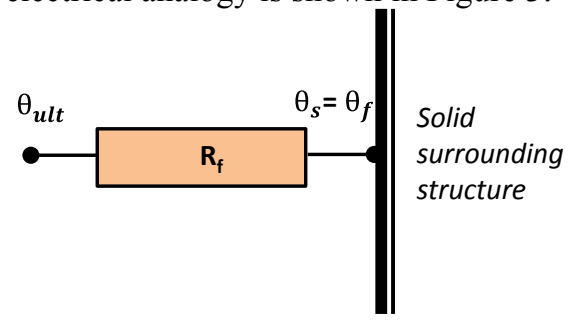

Fig. 3. Electrical analogy of one-zone fire compartment model when neglecting the thermal resistance at the fire exposed surface, i.e. $R_{h, i}=0$ and $\theta_{f}=\theta_{s}$.

According to common heat transfer theory found in several textbooks like [8] the surface temperature increase $\theta_{s}$ can be calculated as a function of time as:

$\theta_{s}=\theta_{g}\left[1-e^{\left(\frac{t}{\tau}\right)} \operatorname{erfc} \sqrt{\frac{t}{\tau}}\right]$

where

$\tau=\frac{k \rho c}{h^{2}}$

and where $h$ is a constant heat transfer coefficient.

Now in analogy with the general solution of the surface temperature of a semi-infinite body, the fire temperature development in a fire compartment surrounded by semi-infinite structures may be written as:

$\theta_{f}=\theta_{s}=\theta_{u l t}\left[1-e^{\left(\frac{t}{\tau_{f}}\right)} \operatorname{erfc} \sqrt{\frac{t}{\tau_{f}}}\right]$

where the parameter $\tau_{f}$ may be identified as a fire compartment time constant for infinitely thick compartment boundaries. The fire compartment time constant may be identified as:

$\tau_{f}=\frac{k \rho c}{\left(\frac{1}{R_{f}}\right)^{2}}=\frac{k \rho c}{\left(c_{p} \alpha_{1} O\right)^{2}}$ 
The relation to standard design time-temperature curves may be demonstrated by prescribing a maximum temperature increase $\theta_{u l t}=\alpha_{2} \chi / c_{p}=1325\left({ }^{\circ} \mathrm{C}\right)$ as derived above. Then if a fire compartment time constant $\tau_{f}=1200 \mathrm{~s}$ is assumed, Eq.21 yields the fire temperature as an analytical solution as:

$\theta_{f}=1325\left[1-e^{\left(\frac{t}{1200}\right)} e r f c \sqrt{\frac{t}{1200}}\right]$

Figure 4 shows the fire temperatures according to this analytical solution (Eq. 23). For comparison the standard fire curve according to ISO 834 and EN 1363-1 and the parametric temperature-time curve for a gamma value of unity according to Eurocode 1 (EN 1991-1-2) are also shown. Note that the three timetemperature curves are almost identical for the first three hours. The difference between the standard curve and the parametric curves is so small that it is not visible in this diagram. The analytically curve goes asymptotically to the ultimate temperature $1325^{\circ} \mathrm{C}$ while the ISO curve is defined by a log function and goes to infinity for long fire durations.

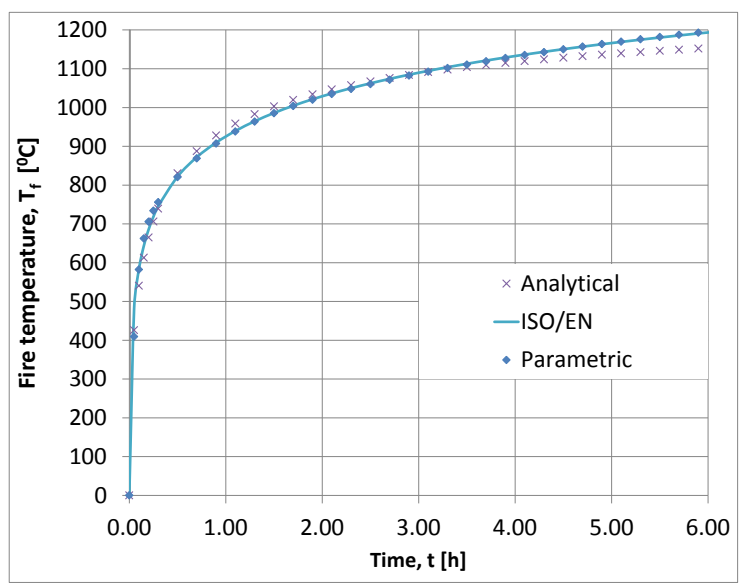

Fig. 4. Comparison between fire temperature rise according to the analytical expression (Eq.23) and the standard ISO 834/EN 1363 curve

In reality the heat transfer resistance between the fire gases and the surfaces of the compartment boundaries must be considered. If it is assumed constant it may be included in this type of simple linear analysis by adding the two resistances $R_{f}$ and $R_{h}$, see Figure 2. The fire compartment time constant then becomes:

$\tau_{f}=\frac{k \rho c}{\left(\frac{1}{R_{f}+R_{h}}\right)^{2}}=\left[\left(R_{f}+R_{h}\right) \sqrt{k \rho c}\right]^{2}$

The surface temperature $\theta_{s}$ may be obtained from Eq. 21 and the fire temperature $\theta_{f}$ from Eq. 15 .

Below is an example to illustrate how fire temperatures of a compartment surrounded by infinitely thick structures with constant properties may be calculated as a function of time.

\section{Example 1}

Calculate the fully developed fire temperature increase after $60 \mathrm{~min}$ in a compartment surrounded by concrete.

a) Neglecting the effects of heat transfer resistance

b) Considering the effects of heat transfer resistance 
Assume an opening factor of $0.04 \mathrm{~m}^{1 / 2}$, a heat transfer coefficient of $h_{t o t}=70 \mathrm{~W} /\left(\mathrm{m}^{2} \mathrm{~K}\right)$, and other fire compartment properties according to Table 2 . For concrete assume the conductivity $k=1.7$, the density $\rho=2300 \mathrm{~kg} / \mathrm{m}^{3}$ and the specific heat capacity $\mathrm{c}=900 \mathrm{~J} /(\mathrm{kg} \mathrm{K})$

\section{Solution:}

a) Eq. 11 yields

$$
R_{f}=\frac{1}{575 \cdot 0.04}=0.0435\left(\mathrm{~m}^{2} \mathrm{~K}\right) / \mathrm{W}
$$

and Eq. 21 yields $\tau_{f}=\frac{3530000}{(575 \cdot 0.04)^{2}}=6673 \mathrm{~s}$.

Thus

$$
\frac{t}{\tau_{f}}=\frac{3600}{6673}=0.54
$$

Eq. 21 yields

$$
\theta_{f}=\theta_{s}=1325\left[1-e^{0.54} \operatorname{erfc} \sqrt{0.54}\right]=646^{\circ} \mathrm{C}
$$

b) Thermal resistance

$$
R_{h}=\frac{1}{h_{t o t}}=\frac{1}{70}=0.0143\left(\mathrm{~m}^{2} \mathrm{~K}\right) / \mathrm{W}
$$

Eq. 24 yields

$$
\tau_{f}=\frac{3530000}{\left(\frac{1}{0.0435+0.0143}\right)^{2}}=11793 \mathrm{sec}
$$

Thus

$$
\frac{t}{\tau_{f}}=\frac{3600}{11793}=0.305
$$

Eq. 21 yields

$$
\theta_{s}=1325\left[1-e^{0.305} \operatorname{erfc} \sqrt{0.305}\right]=544^{\circ} \mathrm{C}
$$

and the fire temperature can be obtained from Eq. 15 as

$$
\theta_{f}=\frac{544 \cdot 0.0435+1325 \cdot 0.0143}{0.0435+0.0143}=737^{\circ} \mathrm{C}
$$

(Thus the fire temperature is $90^{\circ} \mathrm{C}$ higher when the heat transfer resistance is considered.)

\section{Thin compartment boundaries}

An analytical solution of the fire temperatures may also be obtained when the fire compartment is surrounded by structures consisting of a metal core where the all the heat capacity is concentrated. Thus the capacity per unit area $C_{\text {core }}$ may be approximated as lumped into the core as indicated in Figure 5. In the analyses below the heat capacity of any insulating material are either neglected or considered as included in the heat capacity of the core. Figure 6 shows an electrical analogy of how the fire temperature and the core and the surface temperature can be calculated. Figure 6 indicates also the relative temperature increase initially, after some finite time and after a very long time. Since according to the model all inertia is lumped into the core and no inertia is assumed in the insulation layers, the temperature differences between various positions will always be proportional to the corresponding thermal resistances.

In the analyses in this section the heat loss by radiation through the opening is neglected. Otherwise an analytical solution is not possible. 


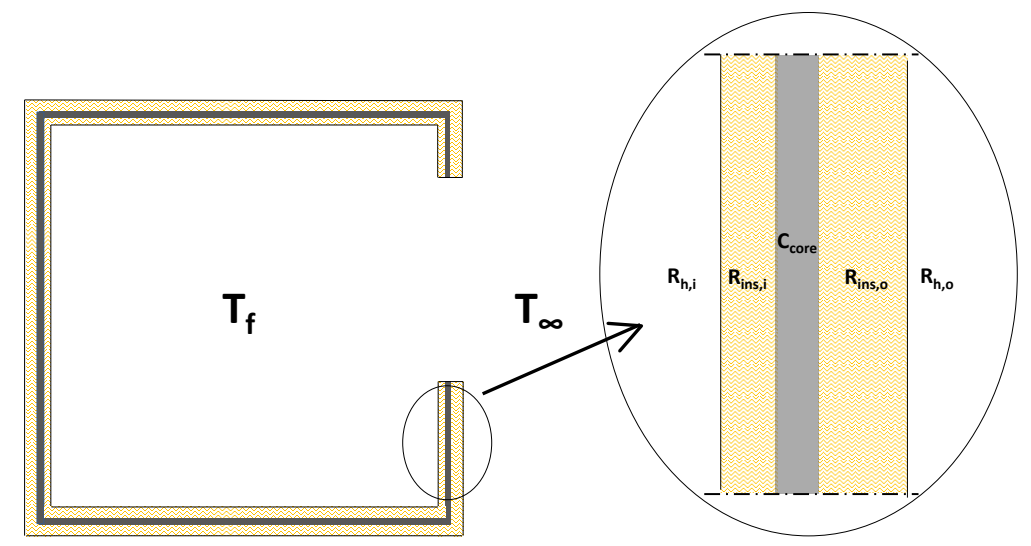

Fig. 5. A fire compartment surrounded by a structure with its heat capacity $C$ assumed concentrated/lumped to a metal core. Thermal resistances $R_{i}$ and $R_{o}$ are assumed on the fire inside and outside, respectively, due to insulation and heat transfer resistance.

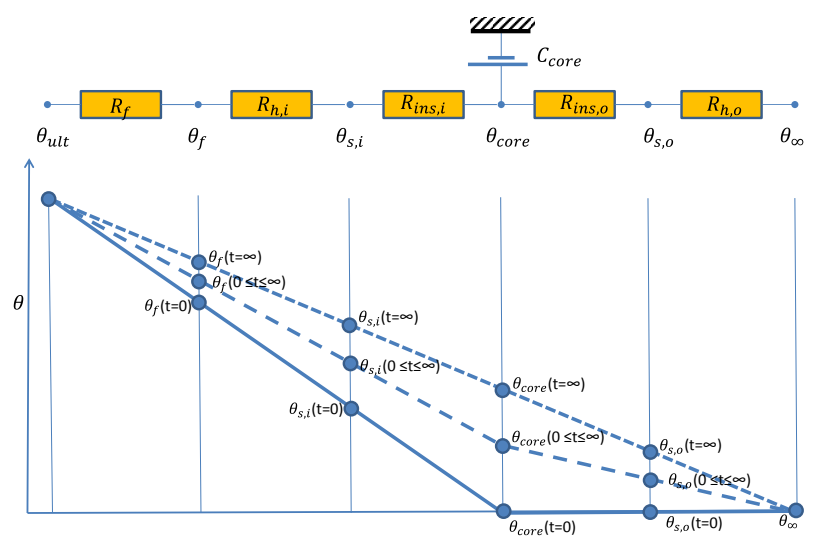

Fig. 6. Electrical analogy of fire compartment model with a thin surrounding structure assuming lumped heat. Temperatures at various points initially $(\mathrm{t}=0)$, after some time $(0 \leq \mathrm{t} \leq \infty)$ and after a very long time $(\mathrm{t}=\infty)$.

The thermal resistance on the inside (fire exposed side) $R_{i}$ of the core may be obtained as the sum of thermal heat transfer resistance and the conductive resistance as:

$R_{i}=R_{h, i}+R_{i n s, i}$

and correspondingly on the outside (unexposed fire side) as:

$R_{o}=R_{h, o}+R_{\text {ins }, o}$

The total thermal resistance of the structure then becomes:

$R_{t o t}=R_{i}+R_{o}$

The conduction resistance of the core is neglected. Then the maximum fire temperature rise may be derived from Eq. 8 as

$\theta_{f}^{\max }=\frac{\chi \alpha_{2}}{c_{p}+\frac{1}{\alpha_{1} O R_{t o t}}}=\frac{R_{t o t}}{R_{f}+R_{t o t}} \theta_{u l t}$

and 
$\theta_{\text {core }}^{\max }=\frac{R_{o}}{R_{f}+R_{\text {tot }}} \theta_{u l t}$

where $\theta_{u l t}$ may be obtained from Eq. 10. $R_{f}$ is defined by Eq. 11. In $R_{i}$ and $R_{o}$ both the heat transfer resistance and possibly the conduction resistance are included. Fig. 7 shows the maximum fire temperature in a non-insulated steel container as a function of the opening factor assuming surface emissivities equal 0.8 and convection heat transfer coefficients according to Eurocode, i.e. $25 \mathrm{~W} /\left(\mathrm{m}^{2} \mathrm{~K}\right)$ and $4 \mathrm{~W} /\left(\mathrm{m}^{2} \mathrm{~K}\right)$ at the fire exposed and the non-fire exposed sides, respectively.

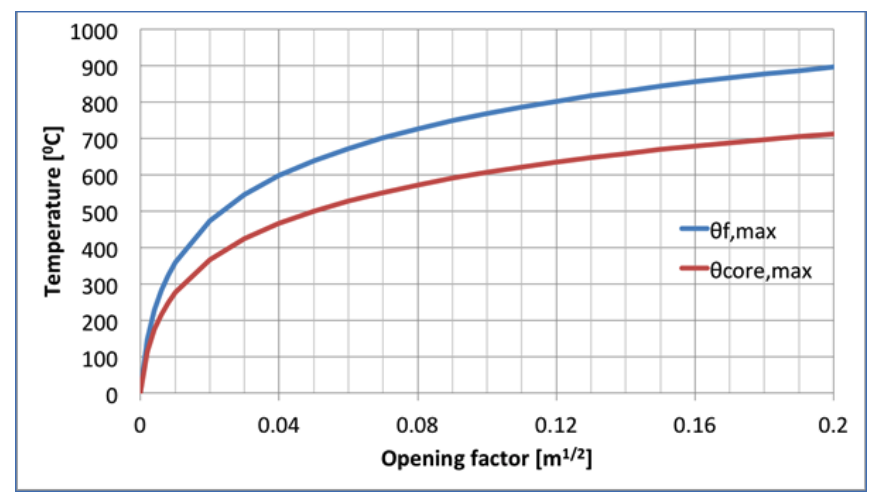

Fig. 7. Maximum fire and steel temperature of a non-insulated steel container as a function of the opening factor [9].

If all the parameters are constant the core temperature increase may be written as a function of time as

$\theta_{\text {core }}=\theta_{u l t}\left[\frac{R_{t o t}}{R_{f}+R_{t o t}}\right]\left(1-e^{-t / \tau_{f}}\right)$

As the insulation is assumed to have negligible heat capacity, the compartment fire temperature increase can be calculated as a weighted average between the ultimate fire and the core temperatures as

$\theta_{f}=\frac{R_{i} \theta_{f}^{u l t}+R_{f} \theta_{c o r e}}{R_{f}+R_{i}}=\theta_{u l t}\left[\frac{R_{i}+R_{f} \frac{R_{o}}{R_{\text {tot }}+R_{f}}\left(1-e^{-t / \tau_{f}}\right)}{R_{f}+R_{t o t}}\right]$

In a corresponding way the fire exposed surface temperature becomes

$\theta_{s, i}=\frac{R_{\text {ins }, i} \theta_{f}^{u l t}+\left(R_{f}+R_{h, i}\right) \theta_{\text {core }}}{R_{f}+R_{i}}$

The fire compartment time constant $\tau_{f}$ is

$\tau_{f}=\frac{C_{\text {core }}}{\frac{1}{R_{f}+R_{i}}+\frac{1}{R_{o}}}$

where $C_{\text {core }}$ is the heat capacity per unit area of the core. 


\section{Example 2}

A fire compartment is surrounded by a $3 \mathrm{~mm}$ thick steel sheet structure with a $12 \mathrm{~mm}$ thick gypsum board mounted on both sides of the core. The opening factor is $0.08 \mathrm{~m}^{1 / 2}$. The total heat transfer coefficient at the fire exposed and the unexposed sides are assumed to be $200 \mathrm{~W} /\left(\mathrm{m}^{2} \mathrm{~K}\right)$ and $40 \mathrm{~W} /\left(\mathrm{m}^{2} \mathrm{~K}\right)$, respectively.
a) Calculate the ultimate fire temperature increase $\theta_{u l t}$
b) Calculate the maximum fire $\theta_{f}^{\max }$ and core $\theta_{\text {core }}^{\max }$ temperature increases.
c) Calculate the core $\theta_{\text {core }}$ and fire $\theta_{f}$ temperature increases after $300 \mathrm{~s}$ of flash-over.

\section{Solution:}

Use fire parameter values as given in Table 2 . The conductivity of gypsum is assumed to be $0.5 \mathrm{~W} /(\mathrm{m} \mathrm{K})$ and the specific heat capacity of steel equal $460 \mathrm{~J} /(\mathrm{kg} \mathrm{K})$ and the density $7850 \mathrm{~kg} / \mathrm{m}^{3}$.

Then

a) Eq. 10 (or Table 2) yields $\theta_{u l t}=1325^{\circ} \mathrm{C}$.
b) The thermal resistance on exposed side

and the thermal resistance on unexposed side

$$
R_{i}=1 / 200+0.012 / 0.5=0.029\left(\mathrm{~m}^{2} \mathrm{~K}\right) / \mathrm{W}
$$

$$
R_{o}=1 / 40^{+} 0.012 / 0.5=0.049\left(\mathrm{~m}^{2} \mathrm{~K}\right) / \mathrm{W}
$$

The fire heat transfer resistance yields

$$
R_{f}=\frac{1}{1150 \cdot 0.5 \cdot 0.08}=0.022\left(\mathrm{~m}^{2} \mathrm{~K}\right) / \mathrm{W}
$$

Then the maximum fire temperature increase (Eq. 28) will be

$$
\theta_{f}^{\max }=\frac{1.52 \cdot 10^{6}}{1.15 \cdot 10^{3}+\frac{1}{0.5 \cdot 0.08 \cdot(0.029+0.049)}}=1034{ }^{\circ} \mathrm{C}
$$

and Eq.29 yields

$$
\theta_{\text {core }}^{\max }=\frac{0.049}{0.022+0.049+0.029} \cdot 1325=649^{\circ} \mathrm{C} .
$$

c) Eq.33 yields $\tau_{f}=270 \mathrm{~s}$ and temperature increase after $300 \mathrm{~s}$ can be obtained from Eq. 30 as

$$
\theta_{\text {core }}=1325 \cdot \frac{0.049}{0.021+0.049+0.29} \cdot\left(1-e^{-\frac{300}{270}}\right)=1325 \cdot 0.494 \cdot 0.67=439{ }^{\circ} \mathrm{C}
$$

and from Eq.31

$$
\theta_{f}^{\max }=\frac{0.029 \cdot 1325+0.021 \cdot 439}{0.021+0.029}=953{ }^{\circ} \mathrm{C} .
$$

\section{Numerical solutions of one-zone model fires}

When the heat transfer model includes parameters varying with temperature including heat radiation through openings or layered compartment boundaries, a numerical procedure must be used. The finite element program Tasef [10] developed for calculating temperature in fire exposed structures allows for mixed boundary conditions and is therefore suitable for such purposes. For this type of calculations the heat transfer resistances have to be assumed constant or neglected.

$$
\dot{q}_{w}^{\prime \prime}=\frac{1}{R_{f}+R_{i}}\left(\frac{\chi \alpha_{2}}{c_{p}}-\theta_{s}\right)+\frac{A_{o}}{A_{t o t}} \frac{1}{\left(1+\frac{R_{h, i}}{R_{f}}\right)} \sigma\left(T_{\infty}^{4}-T_{f}^{4}\right)
$$

The surface temperature can now be calculated with, for example, the finite element code Tasef [10]with the analogue assumptions according to Table 1. A one-dimensional model of the surrounding structure is then assumed. This may then contain several layers of materials, materials with properties varying with 
temperature, structures containing voids or anything that is possible to model with the code available. Work with these type of assumptions are under way at Luleå University of Technology, Sweden.

\section{CONCLUSIONS}

In this paper a new simple calculation method for analytically calculating compartment temperature when flashover is reached has been described. This new method introduces the so called ultimate fire temperature, the maximum temperature which can be reached when there is no energy lost in the compartment surroundings and no radiation lost through the openings. This temperature depends only on the combustion yield $\alpha_{2}$, combustion efficiency $\chi$ and the specific heat capacity of air $c_{p}$, but it is independent of the air mass flow rate, and of the fire compartment geometry and the thermal properties of the compartment boundaries. A value in the order of $\theta_{u l t}=1325^{\circ} \mathrm{C}$ can then be deducted for a combustion efficiency of $50 \%$ and the analytically derived time-temperature development is approximately the same as given in Eurocode 1 (EN 1991-1-2) as parametric temperature-time curves. In reality the heat is lost by radiation through the openings and the combustion efficiency is likely to be higher than $50 \%$. The first fact reduces the maximum temperature possible to reach while the latter would lead to increased temperatures.

In this paper the ultimate temperature for a compartment with semi-infinitely thick walls as well as with thin walls with a steel core and finite insulation has been used to calculate analytically compartment fire temperature. It has been shown that for semi-infinite case the solution match very well with the standard ISO 834/EN 1363-1 curve and with the parametric curves according to EN 1991-1-2. It has also been shown how the maximum fire temperature of a compartment with thin wall depends on the ultimate compartment fire temperature and the total thermal resistance of the surrounding structure.

\section{ACKNOWLEDGEMENTS}

The authors gratefully acknowledge the financial support provided by The Swedish fire research board, Brandforsk, Sweden.

\section{REFERENCES}

[1] Magnusson, S.E., Thelandersson, S., Temperature-Time Curves for the Complete Process of Fire Development - A Theoretical Study of Wood Fuels in Enclosed Spaces, Acta Politechnica Scandinavica, Ci 65, Stockholm, 1970.

[2] Wickström, U., Application of the Standard Fire Curve for Expressing Natural Fires for Design Puposesll, Fire Safety: Science and Engineering, ASTM STP 882, T.Z. Harmathy, Ed., American Society of Testing and Materials, Philadelphia, 1985, pp.145-159.

[3] EN 1991-1-2, Eurocode 1: Actions on structures - Part 1-2: General actions - Actions on structures exposed to fire

[4] Babrauskas, V., Williamsson, R.B. Post-flashover compartment fires: basic of a theoretical model, Fire and materials, vol 2, No. 2, 1978, pp 39-53.

[5] Huggett,C., Estimation of rate of heat release by means of oxygen consumption measurements, Fire and Materials, volume 4, issue2, 1980, pp.61-65

[6] Tewarson, A.. Heat release in fires, Fire and Materials, 4, 1980, pp. 185-191.

[7] Drysdale D. An introduction to fire dynamics. Second edition. John Wiley \& Sons publisher, 1998, p180.

[8] Holman, J.P. Heat transfer, McGraw-Hill Science/Engineering/Math, 10 edition, 2009.

[9] Sundström, O., Gustavsson, S., Simple temperature calculation models for compartment fires, Bachelor thesis, Luleå University of technology, 2012.

http://pure.ltu.se/portal/files/41431736/LTU-EX-2012-41368234.pdf

[10] Wickström, U., TASEF-2 - A Computer Program for Temperature Analysis of Structures Exposed to Fire", Lund Institure of Technology, Department of Structural Mechanics, Report NO. 79-2 (doctoral thesis), Lund, 1979. 